American Journal of Applied Sciences 6 (5): 929-936, 2009

ISSN 1546-9239

(C) 2009 Science Publications

\title{
Development of Dual Fuel Single Cylinder Natural Gas Engine an Analysis and Experimental Investigation for Performance and Emission
}

\author{
Syed Kaleemuddin and G. Amba Prasad Rao \\ Department of Mechanical Engineering, National Institute of Technology Warangal, India
}

\begin{abstract}
The present study reports the experimental investigations carried and upgradation of $395 \mathrm{cc}$ air cooled engine to dual fuel (CNG/Gasoline) application. The original $395 \mathrm{cc}$ direct injection naturally aspirated, air cooled diesel engine was first converted to run on Gasoline by addition of electronic ignition system and reduction in compression ratio to suit both gasoline and CNG application. CFX software has been employed to calculate and improve the cooling capacity of engine with the use of CNG. Materials of major engine components were reviewed to suit CNG application. The engine was subsequently tuned with dual multi-mapped ignition timing for bi-fuel stoichiometric operation on engine dynamometer and then fitted on a 3-Wheeler vehicle. The vehicle was optimized on a chassis dynamometer to meet the proposed Bharat Stage-III norms. The engine has passed current BS-II emission norms with $48 \%$ margin in CO emission and 76\% margin in NMHC (Non-Methane Hydrocarbons) and Extensive trials were conducted on engine and vehicle to optimize with CNG kit and minimum loaded three way cat-con to finally to met proposed BS-III norms.
\end{abstract}

Key words: Dual fuel CNG, performance, emission

\section{INTRODUCTION}

Extensive Research has given a way for a number of alternate fuels to mitigate the problems of fuel crisis and associated environmental degradation. It is not an exaggeration that automotive population has given rise to severe air pollution. The liquid dominated prime movers have driven the vehicles for many years and leaving the danger of its existence. Use of gaseous fuels in for fueling the Engines reduces reactive hydrocarbons and do not pose the problem of vaporization as with the liquid fuels. Two gaseous fuels viz. LPG (Liquid Petroleum Gas) and CNG (Compressed Natural Gas) have attracted the attention of both industry and transportation sectors ${ }^{[1]}$. As domestic sector is dominated by the use of LPG for meting cooking and other allied applications, attention is being diverted towards the use of natural gas on a large scale. Natural gas, a naturally occurring fuel found in oil fields (one of the world's most abundant fossil fuel). It is primarily composed of about $90-95 \%$ methane (CH4), with small traces of additional compounds such as $0-4 \%$ Nitrogen, $4 \%$ ethane and 1$2 \%$ propane Methane has a lower carbon to hydrogen ratio relative to gasoline, so its $\mathrm{CO}_{2}$ emissions are about $22-25 \%$ lower than gasoline. Natural gas is stored in a compressed $(\mathrm{CNG})$ state at room temperatures and also in a liquid (LNG) form at $-160^{\circ} \mathrm{C}$, has an research octane number (RON) of about 127 , is good suited for SI engines, can be run on without knocking on high compression ratios. Due its high auto ignition temperature it is readily suited for SI engines. Table 1 depicts the important properties of $\mathrm{CNG}$, gasoline and diesel fuel.

Natural gas is pressurized to $22 \mathrm{MPa}$ in vehicular storage tanks, so that it has about $1 / 3$ of the volumetric energy density of gasoline. The storage pressure is about 20 times that of propane. Combustion of methane is different from that of liquid hydrocarbon combustion since only carbon-hydrogen bonds are involved and no carbon-carbon bonds, so the combustion process is more likely to be complete, producing less non-methane hydrocarbons. Natural gas has a lower adiabatic flame temperature $(\sim 2240 \mathrm{~K})$ than gasoline $(\sim 2310 \mathrm{~K})$, due to its higher product water content. Operation under lean conditions will also lower the peak combustion temperatures $^{[2]}$. The lower combustion temperatures lower the NO formation rate and produce less engineout $\mathrm{NO}_{\mathrm{x}}$. Natural gas can replace diesel fuel in heavy duty engines with the addition of a spark ignition system. A number of heavy duty diesel engine manufacturers are also producing a dedicated natural gas heavy duty engines. The natural gas fueled engines are operated lean with an equivalence ratio as low as

Corresponding Author: Syed Kaleemuddin, Department of Mechanical Engineering,

National Institute of Technology Warangal, India Tel: +91- 0240-2479340 Fax: +91 -0240 -2479334 
Am. J. Applied Sci., 6 (5): 929-936, 2009

Table 1: Fuel properties

\begin{tabular}{llll}
\hline Property & Gasoline & Diesel & $\mathrm{CNG}$ \\
\hline Chemical formula & $\mathrm{C}_{8} \mathrm{H}_{16}$ & $\mathrm{C}_{12} \mathrm{H}_{26}$ & $\mathrm{CH}_{4}$ \\
State & $\mathrm{Liquid}$ & Liquid & $\mathrm{Gas}$ \\
Energy content & $100 \%$ & $110 \%$ & $25 \%$ \\
Octane rating & $87 \sim 93$ & & $120 \sim 130$ \\
Auto ignition temp. & $225^{\circ} \mathrm{C}$ & $220^{\circ} \mathrm{C}$ & $450^{\circ} \mathrm{C}$ \\
Stoichiometric ratio & 14.7 & 15 & 17.3 \\
\hline
\end{tabular}

0.7. The resulting lower in-cylinder temperatures reduce the $\mathrm{NO}_{\mathrm{x}}$ levels. In the literature, it is observed most of the work on the use of CNG has been carried out on the multi-cylinder water cooled engines or single cylinder water cooled engines experimentally investigated the effect of advanced injection timing on emission characteristics of a diesel engine running on natural gas. The test results showed that alternative fuels exhibit longer ignition delay, with slow burning rates $^{[3]}$. The ignition delay was reduced through advanced injection timing but tended to incur a slight increase in fuel consumption. The $\mathrm{CO}$ and $\mathrm{CO}_{2}$ emissions were reduced through advanced injection timing.

Due to the threat posed by the automotive population, different nations have gone in for setting different stringent emission norms. Thus the engine manufacturing is put under enormous pressure to comply with stringent emission norms.

Present research reports the experimental investigations carried out on light duty automotive engine to employ $\mathrm{CNG}$ and to comply with the proposed new emissions standards. The investigations include:

- Conversion of $395 \mathrm{cc}$ high speed diesel engine into spark-ignition engine

- Design modification was carried for $\mathrm{CNG}$ compatible solution

- CFD analysis to improve the cooling system

- Spark ignition engine was tuned for bi-fuel stoichiometric operation on CNG as fuel

- Performance and emission tests were carried out engine dynamometer and chassis dynamometer and

- Finally, CNG fueled engine was optimized for emission on reference 3 -wheeler vehicle to achieve equivalent mileage as diesel

\section{MATERIAL AND METHODS}

The diesel engine complying with BS-II emission norms was adopted to convert it into spark-ignition engine whose specification along with test vehicle details is illustrated in below Table 2 .
Table 2: Diesel engine specification and vehicle details

\begin{tabular}{ll}
\hline Parameter & Specification \\
\hline Engine type & DI, Naturally aspirated, Air cooled \\
Bore×Stroke, mm & $86 \times 68$ \\
Number of cylinders & 1 \\
Displacement, cc & 395 \\
Compression ratio & $18: 1$ \\
Fuel pump & PFE 1Q \\
Injector nozzle type & P type DSLA \\
Vehicles & Load carrier \\
Unladen mass, kg & 384 \\
Reference mass, kg & 534 \\
Gross Vehicle Weight, kg & 995 \\
Gear box & Four speed \\
Differential ratio & 2.385 \\
Tyre size & $4.5 \times 10$ " 8PR \\
\hline
\end{tabular}

Spark ignition engine design was done by modifying existing cylinder head, Piston assembly, Flywheel and replacing fuel injection system with electronic ignition system on engine. Valve timing of existing diesel was found suitable for spark ignition engine and was unaltered.

Cylinder head: Diesel engine intake and exhaust port with average flow coefficient of 0.274 for intake port and 0.308 for exhaust port was retained in order to build a gasoline engine with typical swirl cylinder head. The flow coefficients were measure in accordance with procedure laid down by Ricardo ${ }^{[4,5]}$, The decision of same cylinder head adopting was taken in order to commonise machining of cylinder head for both production running diesel engine and newly developed spark-ignition engine also it reduces tooling cost. Spark plug thread tapping was made at $20^{\circ}$ inclination in the cylinder head was in place of diesel injector, so that spark plug is located centrally with required spark plug protrusion in order to produce short flame travel which reflect in rapid and relatively complete combustion.

Flywheel weight reduction: Since gasoline engine is quantity governed lightweight flywheel is preferred hence additional base diesel engine flywheel was machined to reduce its weight to $6.25 \mathrm{~kg}$ from existing $14 \mathrm{~kg}$.

Compression ratio: Diesel engine compression ratio of 18:1 was changed to optimum working compression ratio of 9:1 for spark ignition engine. Piston toping clearance was increased from $0.75-7.4 \mathrm{~mm}$ to achieve spark ignition compression ratio as illustrated in Fig. 1. Spark ignition engine working compression ratio of 9:1 was kept on higher side in order to adopt it for CNG as a fuel, which demands for higher compression ratio due to its high auto ignition temperature and low calorific value $^{[6]}$. 9:1 compression ratio was achieved by 


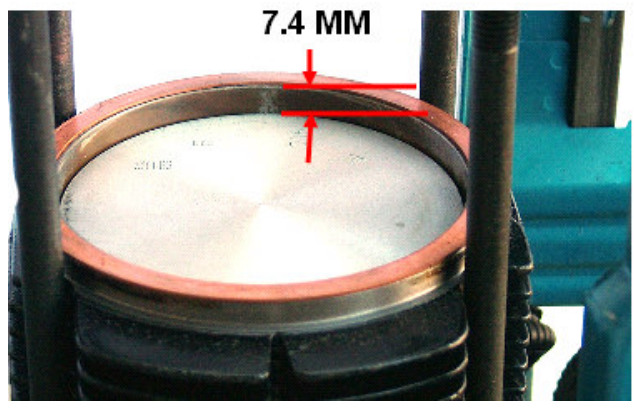

Fig. 1: Pan cake combustion chamber

modifying existing reentrant piston crown to pan cake combustion chamber. Pan cake combustion chamber piston was adopted to avoid hot spot during spark ignition combustion as cylinder was having intake swirl port.

Carburetor selection: Mechanical controlled variable depression carburetor with piston type throttle was selected. Were the throttle is situated in the venture zone itself, area of venturi was varied by throttling carburetor piston up and down to provide the right quantity of mixture to meet the engine operating conditions $^{[7]}$. The quantity of fuel delivered was controlled by various jets and passages and metering needle moving inside the calibrated orifices. The metering needle is attached to throttle itself. Carburetor piston was anodized in order to take care of wear and abrasion during dry run of CNG.

Electronic ignition system: From the base diesel engine, fuel injection system and governing mechanism were removed and spark ignition system was introduced with electronic multi mapped DC Igniter with pulsar pickup ${ }^{[7,8]}$. High tension coil with high energy capacity was used in order to care delay combustion due to high auto ignition temperature of CNG fuel. In order to take care valve train mechanical safety higher engine speed cut off was introduce in DC igniter which cut off spark from spark plug as soon as engine reaches $4100 \mathrm{rpm}$.

Spark plug selection: On assessment twin electrode resistive spark plug was adopted on engine in case of twin electrode plugs ignition spark selects the best route to take from the centre electrode to the ground electrode $^{[7,8]}$. The possible spark path are four as against one in single electrode spark plug. This increase the probability of ignition and improve the acceleration startability even for delayed fuel characteristic of CNG. On assessment, resistive spark plug has shown compactable for electromagnetic interference. The spark plug temperature was recorded on engine and as well on the vehicle by running the vehicle at different speeds. The temperature was found $200^{\circ} \mathrm{C}$ higher but within acceptable range for CNG application. This is because of more heat losses compared to diesel engine even after increasing cooling surface area.

Cooling system improvement-CFD analysis: Gasoline engines mostly run hotter as compared to diesel engine due its homogeneous combustion process as compared to lean burn heterogeneous nature of diesel combustion process. Further, CNG engine will run hotter than gasoline engine due to delay in combustion process because of its higher auto ignition temperature and lower specific weight. To make CNG compatible analysis was done on existing diesel engine cooling system through CFX (Computational Fluid Dynamic) software. From the CFD analysis it was concluded that existing surface area was adequate for diesel application only. Specially for CNG application additional surface area of $15 \%$ was required for adequate cooling. To achieve increase in surface area for effective cooling, the number of fins on the cylinder head and cylinder barrel was increased without major decrease in space between the fins hence the thermal balancing of the cylinder head and block were retained. The flow rate of fan is increased by $10-15 \%$, by modifying the blade design. The changes are made in the air-shroud and back-plate for accommodating the fan design as shown in Fig. 2.

Turbulent Kinetic Energy profile of CFD analysis of existing system is shown in Fig. 3 where poor air velocity is causing excess heat energy loss leading to over heating of engine and drop in performance. Figure 4 shows for improved system where air velocity has improved engine cooling reducing hot spot from turbulent kinetic energy profile. The analysis has given $10-12 \%$ improvement in engine cooling on actual engine.

CNG compactable material: As CNG operated engine was running hotter by hundred degree centigrade in $\mathrm{CNG}$ as compared to gasoline. Engine material of cylinder head, valve and valve seat insert were reviewed for CNG compatibility ${ }^{[9,10]}$. Cylinder head material was upgraded with silicon copper high alloy material to retain hardness at elevated temperature, valves material was reviewed from mono metal with bimetal valve with satellite coating on valve head in order to avoid premature wear due dryness of CNG fuel. Cobalt base alloy was used in valve seat inserts which remain intact even at elevated temperatures. 
Am. J. Applied Sci., 6 (5): 929-936, 2009

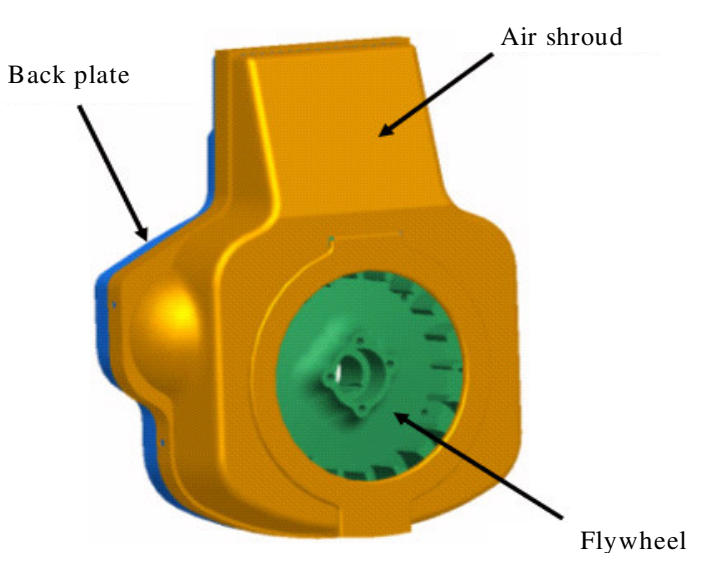

Fig. 2: Cooling system of engine

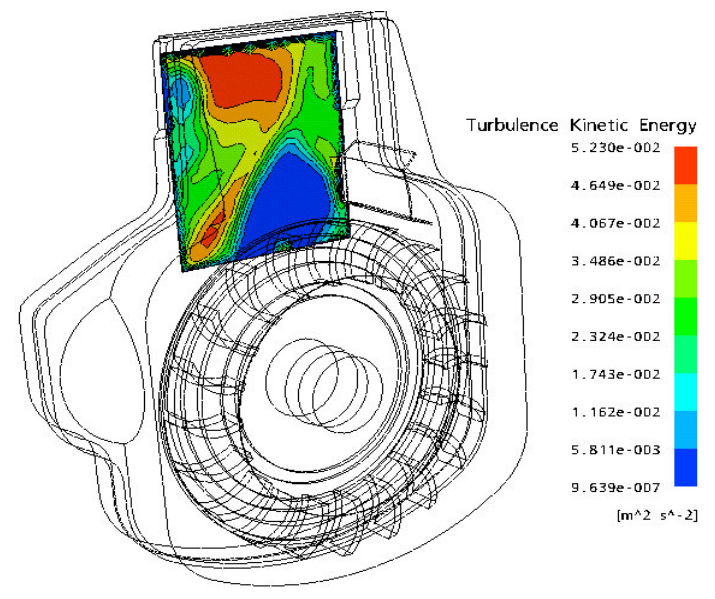

Fig. 3: Existing system turbulent kinetic energy profile

\section{Experimental method}

Ignition timing optimization: Ignition timing was mapped for each engine speed and load for better engine performance and fuel economy. Figure 5 shows schematic layout of engine setup use for experimental research.

To compensate for dual Gasoline and CNG application, dual ignition timing curve was mapped to achieve better power, torque and over all performance and also to meet the engineering target for mass emission test on chassis dynamometer. Variable ignition timing of $15^{\circ}$ btdc at low idling engine speed to $25^{\circ}$ btdc at rated engine speed was optimized for gasoline mode and $29^{\circ}$ btdc at rated speed was optimized for CNG mode as shown in Fig. 6. Selection of respective curve is sensed through change over switch of CNG kit.

Engine optimization on engine dynamometer: During engine optimization in $\mathrm{CNG}$ mode intake

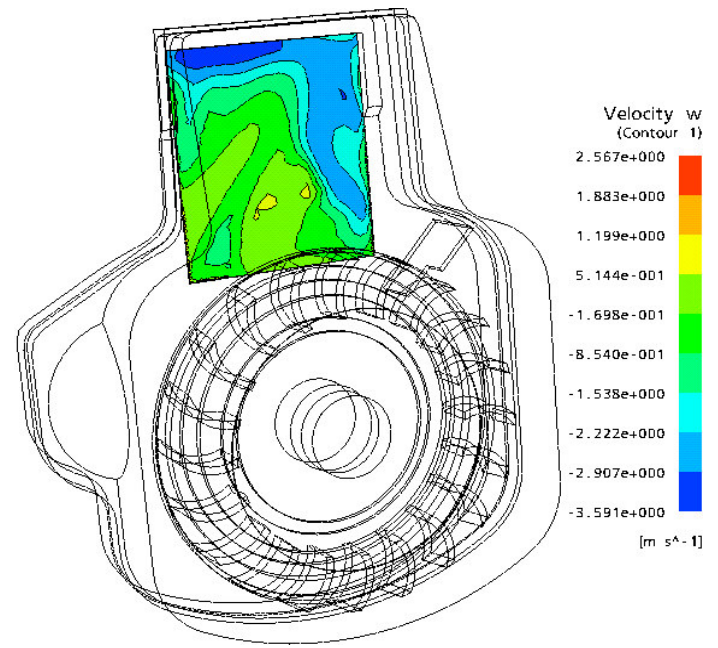

Fig. 4: Improved system turbulent kinetic energy profile

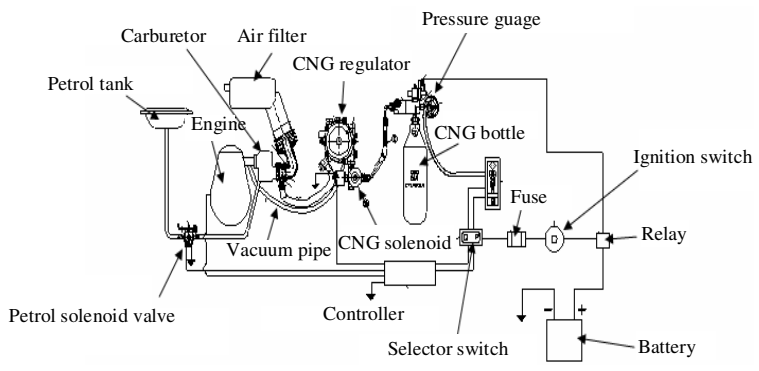

Fig. 5: Schematic layout of engine with CNG system

system was becoming more sensitive especially in part load condition where effective compression ratio decrease due to homogenous combustion process. To study on stoichiometric air to fuel ratio in gasoline and CNG intake system was optimized ${ }^{[11]}$. During initial engine performance there was drop in volumetric efficiency observed, drop in volumetric efficiency was mostly due to poor CNG fuel and pulsation effect at higher engine speed. Many trials was done by adding volume in intake system to reduce pulsation effect which results in increasing volumetric efficiency. Resonator optimum volume of $5 \mathrm{~L}$ could achieve nearly equivalent volumetric efficiency as of diesel. Figure 7 shows the trends of volumetric efficiency with different volume in intake system.

Combustion pressure measurement: Combustion pressure measurement was done by AVL endoscope. With CNG as fuel there was drop in combustion pressure to 36 bar as against 55 bar of diesel as show in Fig. 8.This drop in combustion pressure is significance as compression ratio for CNG is lesser then diesel 


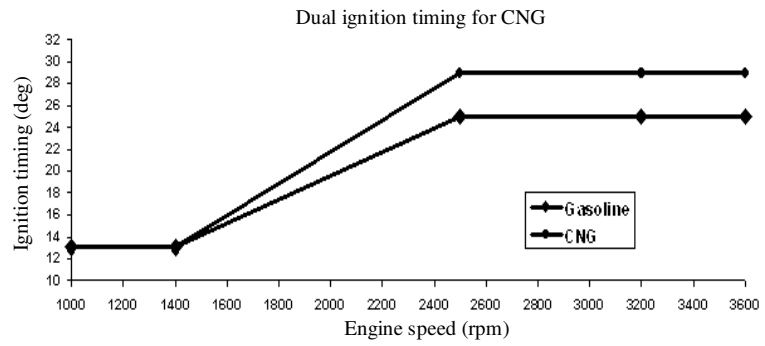

Fig. 6: Dual timing ignition curve

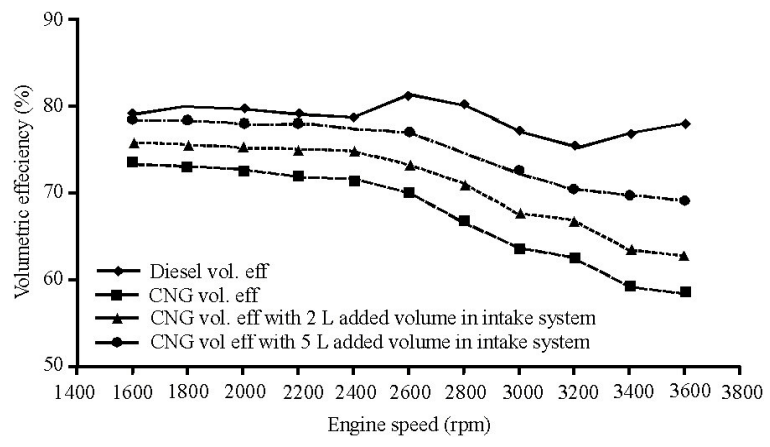

Fig. 7: Trends of volumetric efficiency

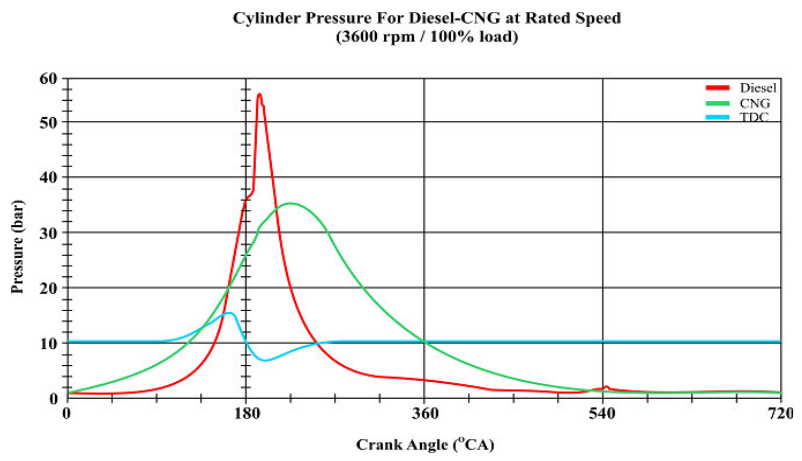

Fig. 8: Combustion pressure at rated speed

engine .Also CNG fuel burn late due to its high auto ignition temperature and also energy density of CNG is lower then diesel. Maximum combustion pressure in CNG was recorded at 17 crank degrees after TDC this due advance ignition timing. Where as maximum combustion pressure in diesel was observed at 12 crank degrees after TDC due to its retarded injection timing.

Optimization of fuel flow: Since CNG operation was in open loop, optimization of fuel flow has been optimized on max torque point in order to get optimum operating lambda and best power which has also enable stability in idle operation of the engine ${ }^{[12]}$. It was decided to map the engine from $1600-3600 \mathrm{rpm}$, at
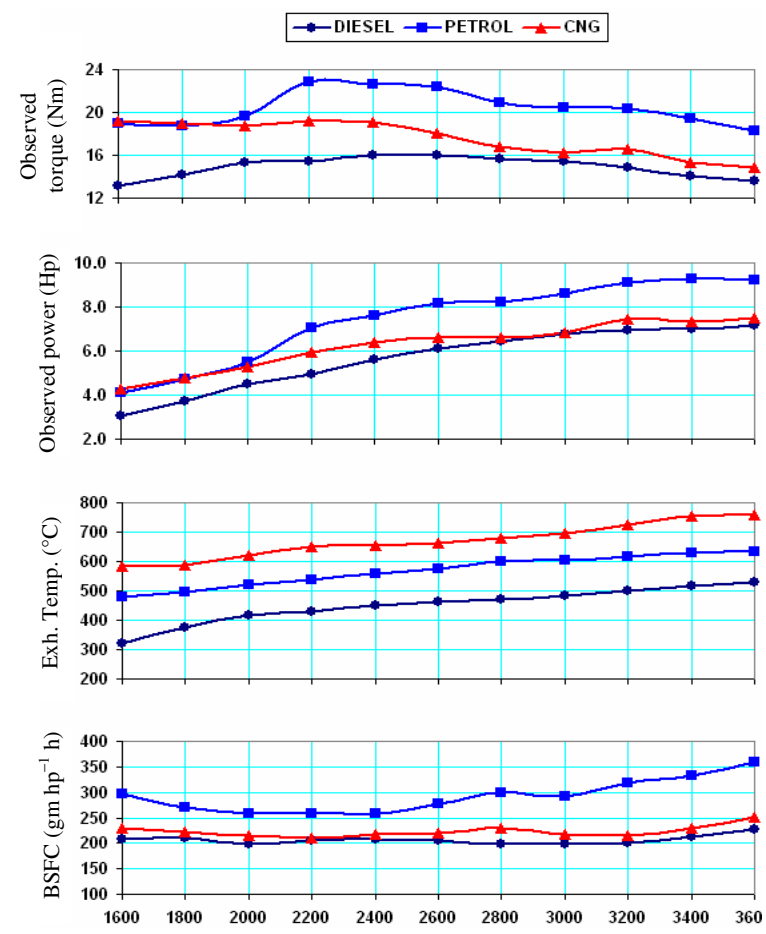

Fig. 9: Full throttle performance comparison plot

the interval of $200 \mathrm{rpm}$ at different load and speed condition. Engine parameters were also recorded for power, bsfc, exhaust temperature and back pressure with different ignition timing to achieve best fuel consumption.

Engine full throttle performance in CNG was found to be better then diesel engine performance which is shown in Fig. 8. Lambda was maintained between 1.051.1 through full load performance as shown in Fig. 9.

\section{RESULT AND DISCUSSION}

Due to lower specific weight of CNG there was drop in engine volumetric efficiency in CNG mode also lower compression ratio has demanded engine to run advance for better engine performance. To meet Maximum Braking Torque (MBT) engine has to achieve peak combustion pressure which is possible if its ideal burn duration is achieved. With advance in ignition timing ideal burn duration of fuel mixture increases which improves engine torque Fig. 10 show trends in observed engine torque with respect to advance ignition timing. Subsequently engine power improves which is shown in Fig. 11.

With retarded ignition timing there was increase in exhaust temperature as illustrate in Fig. 12 and also there was drop in torque at higher engine speed as 


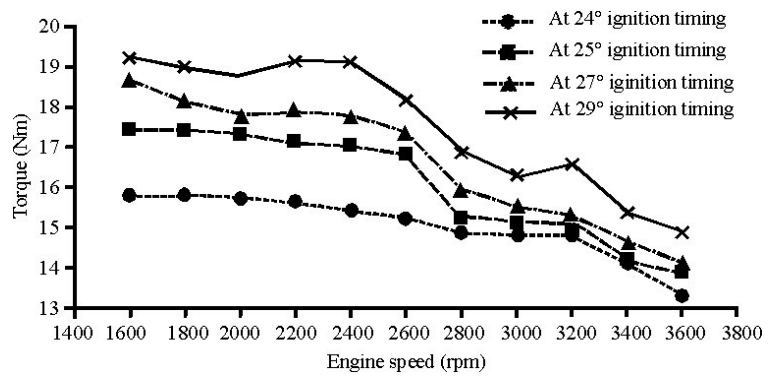

Fig. 10: Shows the trends of observed torque with respect to different ignition timing

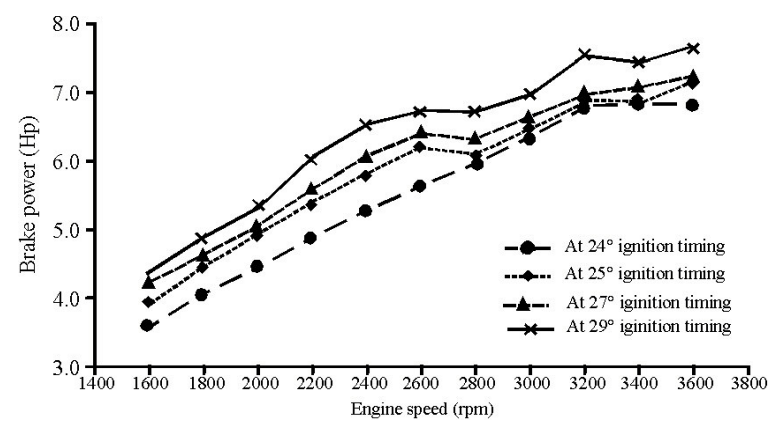

Fig. 11: Power trends with different ignition timing

charge density is function of gas pressure and gas temperature. Higher engine speed lean down air to fuel ratio and combustion temperature increases.

Since Natural gas has $1 / 3$ of the volumetric energy density of gasoline and diesel also alternative fuels exhibit longer ignition delay, with slow burning rates due to its high auto ignition temperature. The ignition delay was reduced through advanced injection timing which has shown in improvement in bsfc as shown in Fig. 13, however best CNG bsfc was still inferior to diesel bsfc.

Experimental study was planned with open loop CNG kit system on engine. It was observed that lambda (excess air factor) setting plays an important role on engine performance. With increase in intake volume lambda was merging towards unity to run engine on stoichiometric air fuel ratio. Trends of lambda with different intake volume is show in Fig. 14.

CNG Fuel flow is adjusted to achieve the required power and good emission and also to operate the lambda in narrow band. Apart from engine dynamometer the fuel flow is optimized on chassis dynamometer. Position of power screw is optimized in such a way that lambda remains in a tolerance band close to unity at full throttle as well as part throttle application. Mass emission was recorded on three wheeler vehicle on chassis dynamometer. Result has

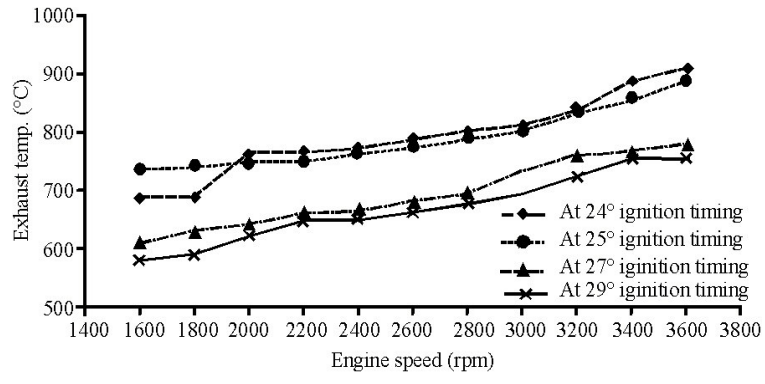

Fig. 12: Trend of exhaust temperature with different ignition timing

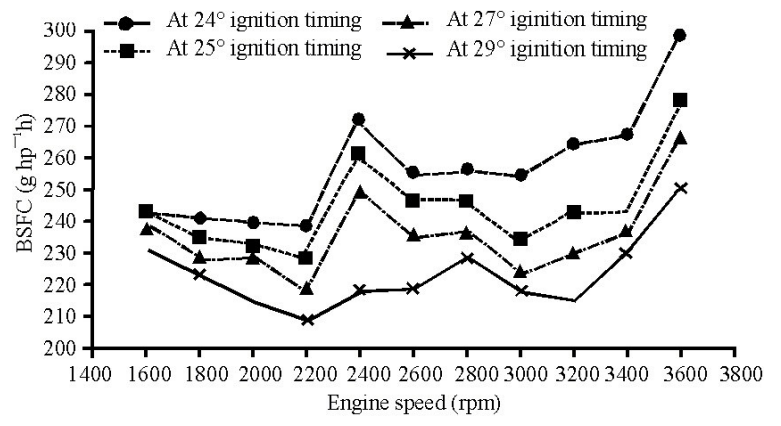

Fig. 13: BSFC trends with different ignition timing

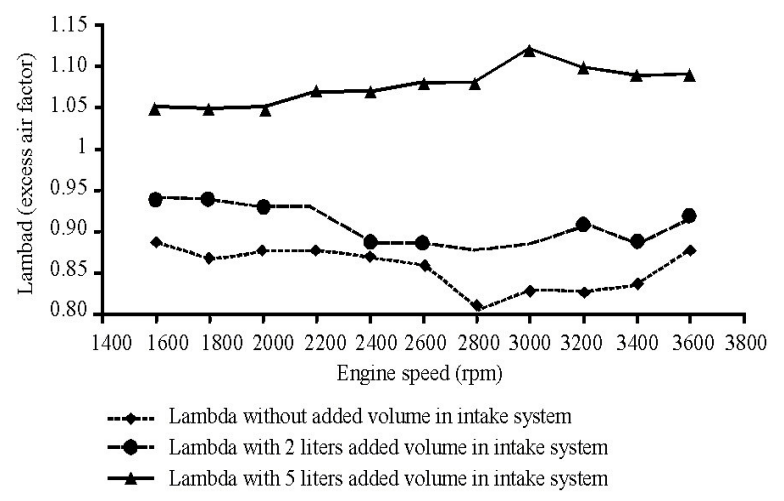

Fig. 14: Trend in lambda with different intake system

shown substantial reduction in over all emissions. $\mathrm{CO}_{2}$ emission was much lower as compare to diesel $\mathrm{CO}_{2}$ emission as shown in Fig. 15. This is due to lower carbon proportion in $\mathrm{CNG}$ as compare to diesel fuel.

During the optimization $5 \mathrm{~g} \mathrm{cuft}^{-1}$ cat.con. with Platinum : Rhodium ratio of $3: 1$ loading was tried to achieve the emission on reference three wheeler vehicle on Indian Driving Cycle with its coast down equation. Emission were measured with Horiba analyzer on vehicle chassis dynamometer. The achieved result are shown in Fig. 16. BS-II (Bharat Stage-II ) emission norms was achieved with $90 \%$ margin in $\mathrm{CO}$ emission 


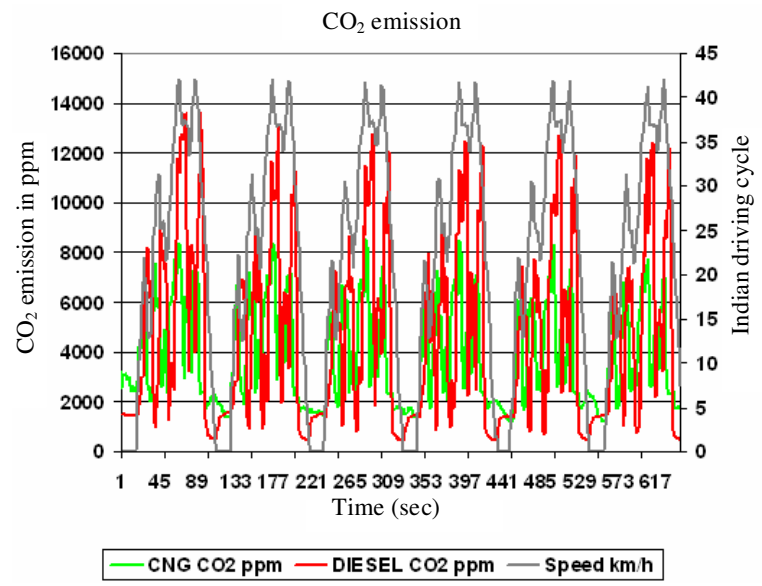

Fig. 15: Diesel and $\mathrm{CNG} \mathrm{CO}_{2}$ emission comparison

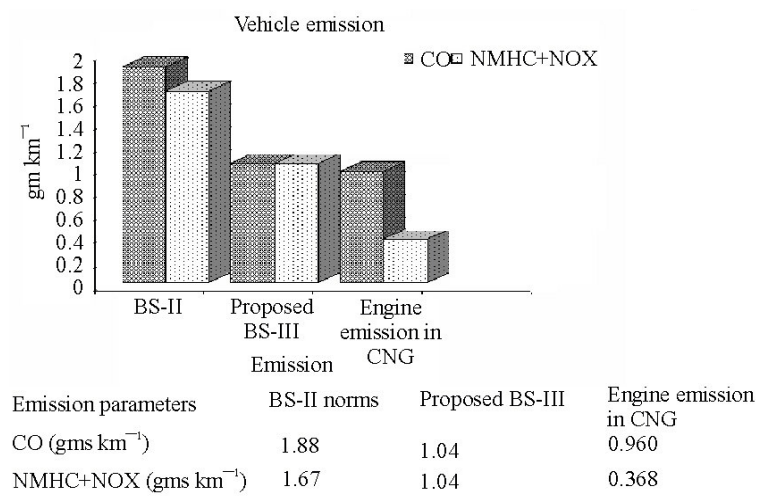

Fig. 16: Vehicle emission result

and $44 \%$ margin in NMHC+NOx which well within proposed BS-III emission limits.

\section{CONCLUSION}

- Existing diesel engine is successfully converted into dual fuel gasoline $\mathrm{CNG}$ engine with dual multi mapped ignition timing

- CNG full throttle performance was found better then existing diesel engine performance in terms of torque and power

- Spark ignition engine has demanded $15 \%$ more engine cooling as compare to existing diesel engine

- Spark ignition engine has passed current BS-II emission norms in CNG as dual fuel application on three wheeler vehicle with $90 \%$ margin in $\mathrm{CO}$ emission and $44 \%$ margin in NMHC+NOx

- With CNG there is $15 \%$ reduction in $\mathrm{CO}_{2}$ emission as compare to Diesel emission
- Spark ignition engine has also passed proposed BSIII emission norms in CNG as dual fuel application on three wheeler vehicle

\section{ACKNOWLEDGEMENT}

The author wishes to express their appreciation to Mr. S.K. Basu Sr. Vice President, Mr. B.P Jetty Vice president of Greaves Cotton Limited granting permission to publish this study. The authors would also like to thank their colleagues from Greaves Cotton Research and technology center for their esteem cooperation during carrying out this research.

\section{REFERENCES}

1. Krishnan. S. and S.D. Rairikar, 2005. Gasoline to gas-revolution. Symposium on International Automotive Technology, Jan. 19-22, Publisher ARAI India, pp: 483-490, SAE Paper 2005-26-33 http://www.sae.org/technical/papers/2005-26-033

2. Rajashekar Swamy. K., 2001. Study and development of lean burn systems on small 4stroke gasoline engine. SAE paper 2001-01-1801 14222. Symposium on International Automotive Technology, Jan. 10-13, Publisher ARAI India, pp: 187-204. http://www.sae.org/technical/papers/ 2001-01-1801.

3. Nafis Ahmad, M.K. Gajendra Babu and A.Ramesh 2005. Experimenatal investigation of different paramaterss affecting the performance of cngdiesel dual fuel Engine SAE paper 2005- 01-3767. Publisher SAE International ISBN: 978-0-76801689-5. http://www.sae.org/technical/papers/200501-3767.

4. Patil., A.S., V.G. Halbe, 2005. A system approach to automotive air intake system development. SAE paper 2005-26-011, Symposium on International Automotive Technology, Jan. 19-22, Publisher ARAI India, pp: 287-300. http://www.sae.org/technical/papers/2005-26-011

5. Blair, G.P., 2001. Maps of discharge coefficients for valves., Ports and throttles. SAE Paper 2001-011798/4219, Small Engine Technology Conference, Nov. 28-30, PISA Italy, pp: 85-98, Publisher Edizioni ETS, http://www.sae.org/technical/ papers/2001-01-1798.

6. Iyengar, K.S. 2007. Development of BS-III CNG Engine for a Light Commercial Vehicle, 2007-26028 Symposium of Automotive Technology 2007. Jan. 17-20, Publisher ARAI India, pp: 484-492, http://www.sae.org/technical/papers/2007-26-028 
7. Robert Bosch Gmb, H., 2006. Gasoline Engine Management. 3nd Edn. Bentley Publishers, 1734 Massachusetts Avenue Cambridge MA02138USA $\begin{array}{llll}\text { ISBN } & 0 & 8376 & 1390\end{array}$ http:/www.bentleypublishers.com/product.htm?cod $\mathrm{e}=\mathrm{H} 012$.

8. van der Weide, J., 1994. Development of An Optimized CNG Passenger Car With Petrol LimpHome System, 940760. http://www.sae.org/technical/papers/940760

9. Kimihiko Ando, Akira Manabe and Akio Yasuda, 2005. Hardfaced valve and $\mathrm{P} / \mathrm{M}$ valve seat system for CNG and LPG fuel engines. SAE Paper 200501-0718, SAE World congress Detroit, Michigan, April 11-14, Publisher SAE International, http://www.sae.org/technical/papers/2005-01-0718

10. Keyoung Jin Chun, Jae Soo Hong, Ho Jung Lee, Deog Yeong Kim, Jeoun kiu I.M, 2004. A study of engine valve and seat insert wearing depending on speed change. SAE Paper 2004-01-1655 SAE World congress Detroit, Michigan, March 8-11, Publisher SAE International, http://www.sae.org/technical/papers/2004-01-1655
11. Blair, G.P., 2001. Exhaust tuning on a four stroke engine, experimental and simulation. Small Engine Technology Conference, SAE Paper 200101 1797/4218, Small Engine Technology Conference, Nov. 28-30, PISA Italy, Publisher Edizioni ETS, pp: 71-85. http://www.sae.org/technical/papers/2001-01-1797

12. Ghosh, B., 2005. Development in new foil structures for metallic substrates (catalytic converters) and their applications on $2 / 3$ wheeled vehicles. SAE Paper 2005-26-025 Symposium of Automotive Technology 2005. Jan. 19-22, Publisher ARAI India, pp: 419-426. http://www.sae.org/technical/papers/2005-26-025 